JURNAL PENDIDIKAN, p-ISSN 2715-095X, e-ISSN 2686-5041

Volume 30, No.3, Nopember 2021 (529-534)

Online: http://journal.univetbantara.ac.id/index.php/jp

\title{
Best Practice \\ Menulis Cerita Pendek dengan Model Pembelajaran "CANTIK" Bagi Siswa SMA Negeri 1 Tawangsari Tahun Pelajaran 2019/2020
}

\author{
Yuni Setyaningsih
}

SMA Negeri 1 Tawangsari, Kabupaten Sukoharjo. E-mail: yunisetyaningsih7@gmail.com

Received: Oktober 27, $2021 \quad$ Accepted: Oktober 29, $2021 \quad$ Online Published: Nopember 08, 2021

\begin{abstract}
Abstrak: Penelitian ini bertujuan untuk 1) mengetahui Teknik penulisan cerpen dengan model pembelajaran "CANTIK", 2) meningkatkan keterampilan peserta didik dalam menulis cerpen. Dalam penelitian ini yang bertindak sebagai subjek adalah guru dan siswa kelas XI MIPA1 SMA N 1 Tawangsari semester genap tahun pelajaran 2019/2020. Objek penelitian secara umum adalah pelaksanaan pembelajaran menulis cerita pendek. Data diperoleh dengan teknik pemberian tugas menulis cerpen, observasi dan dokumentasi. Data dianalisis menggunakan metode deskripsi kualitatif yaitu penyajian data dan penarikan kesimpulan/verifikasi. Hasil penelitian menunjukkan bahwa pembelajaran menulis cerita pendek pada siswa kelas XI MIPA1 SMA N 1 Tawangsari semester genap tahun pelajaran 2019/2020 dilaksanakan berdasarkan Kurikulum 2013, silabus pembelajaran Bahasa Indonesia kelas XI, dan dilaksanakan sesuai RPP Bahasa Indonesia bahan ajar teks cerita pendek. Kendala yang dihadapi dalam pembelajaran menulis cerita pendek berupa 1) belum diterapkannya model pembelajaran yang tepat dalam pembelajaran menulis cerpen, 2) rendahnya motivasi para siswa dalam mengikuti pembelajaran menulis cerpen, 3) menurunnya konsentrasi peserta didik ketika pembelajaran Bahasa Indonesia terjadwal pada jam-jam akhir pembelajaran. Cara mengatasi kendala tersebut adalah (a) penerapan metode pembelajaran menulis cerpen yang tepat dan menarik bagi peserta didik, (b) memberikan motivasi dan pencerahan kepada peserta didik tentang manfaat memiliki kemampuan menulis cerita pendek dalam kehidupan sehari-hari. (c) variasi alokasi jadwal pembelajaran menulis cerita pendek.
\end{abstract}

Kata-kata Kunci: Implementasi Model Pembelajaran "CANTIK"

\section{Writing Short Stories with the "CANTIK" Learning Model for Students of SMA Negeri 1 Tawangsari Academic Year 2019/2020}

\author{
Yuni Setyaningsih
}

\author{
SMA Negeri 1 Tawangsari, Sukoharjo Regency.E-mail: yunisetyaningsih7@gmail.com
}

\begin{abstract}
This study aims to 1) find out the technique of writing short stories with the "CANTIK learning model", 2) improve students' skills in writing short stories. In this study, the subjects were teachers and students of class XI MIPAI SMA N 1 Tawangsari in the even semester of the 2019/2020 school year. The object of research in general is the implementation of learning to write short stories. The data obtained by the technique of giving short story writing assignments, observation and documentation. The data were analyzed using a qualitative description method, namely data presentation and conclusion drawing/verification. The results showed that
\end{abstract}


learning to write short stories in class XI MIPA1 SMA N 1 Tawangsari in the even semester of the 2019/2020 school year was carried out based on the 2013 Curriculum, the Indonesian language learning syllabus for class XI, and was carried out according to the Indonesian RPP for short story text teaching materials. The obstacles faced in learning to write short stories are 1) the implementation of the right learning model in learning to write short stories, 2) the low motivation of students in participating in short story writing lessons, 3) decreased concentration of students when learning Indonesian is scheduled in the final hours. learning. The ways to overcome these obstacles are (a) the application of learning methods to write short stories that are appropriate and interesting for students, (b) provide motivation and enlightenment to students about the benefits of having the ability to write short stories in everyday life. (c) variations in the allocation of learning schedules for writing short stories.

Keywords: Implementation of "CANTIK" Learning Model

\section{Pendahuluan}

Pembelajaran menulis merupakan salah satu aspek keterampilan berbahasa yang bersifat produktif. Pembelajaran menulis sangat penting dalam pendidikan karena dapat membantu siswa berpikir, mengungkapkan gagasan, dan memecahkan masalah. Menulis adalah salah satu bentuk berfikir yang juga merupakan alat untuk membuat orang lain yang membaca berfikir. Dengan menulis, siswa mampu mengkontruksikan berbagai ilmu pengetahuan yang dimiliki dalam bentuk tulisan, baik dalam bentuk esai, artikel, laporan ilmiah, cerpen, dan karya tulis lainnya. Menurut Mimi (20!4) menulis merupakan keterampilan berbahasa yang paling tinggi karena seseorang baru akan terampil menulis ketika ia mampu menuliskan apa yang ia peroleh dari pengalaman yang telah ia dapatkan. Maka dari itu, pembelajaran menulis perlu diperhatikan dan diberi pengarahan agar siswa mempunyai minat terhadap pembelajaran menulis, terutama menulis cerpen yang membutuhkan inspirasi dan daya imajinasi, agar siswa mampu menghasilkan karya cerpen yang baik dan menarik. Menurut Listini dan Saraswati (2017) bahwa kemampuan menulis siswa perlu diperhatikan oleh para pendidik, karena untuk menunjang keberhasilan dalam proses akademik.

Menurut Mastini, sarwiji dan Sumarti (2016) cerita pendek adalah karya sastra berbentuk prosa yang isi ceritanya mengisahkan permasalahan kehidupan suatu tokoh yang diceritakan secara ringkas dan berfokus pada suatu tokoh, serta dimediakan secara lisan ataupun tulis. Menulis cerpen adalah menemukan masalah, menemukan persoalannya, menemukan konflik, menceritakan pengalaman, dan menghadirkan pengalaman itu sendiri melalui isinya. Menceritakan pengalaman berarti narasi, yang sifatnya hanya memberitahukan dan memberi informasi, sedangkan menghadirkan pengalaman berarti menghidupkan kejadian kssembali secara utuh. Agar dapat menulis cerpen dengan baik, perlu adanya latihan-latihan, membaca karya-karya sastra, berusaha menambah pengetahuan dan pengalaman, mempunyai kecakapan menulis, dan mempunyai disiplin untuk terus menulis secara tetap (Sumardjo, 2004: 42).

Menurut Pranoto (2007: 21), menulis cerpen memerlukan proses kreatif. Proses itu merupakan rangkaian kegiatan yaitu menciptakan suatu karya berupa cerita pendek, yang 
semula tidak ada menjadi ada. Keberadaanya begitu jelas, nyata, dapat dibaca dan meninggalkan kesan. William Faulkner (dalam Pranoto, 2007: 21) mengatakan bahwa seseorang yang menulis cerpen harus serius, tidak sekedar mengebor melainkan menggali lobang. Semakin menganga di dalam lobang itu, semakin sempurnalah karya yang ditulisnya. Tentu saja berbeda dengan lobang yang sesungguhnya dengan 'lobang cerpen'. Yang dimaksud dengan kedalaman 'lobang cerpen' adalah seberapa kuatnya bobot isi cerpen tersebut, sehingga pembacanya mampu menimba substansi yang ada di dalamnya. Substansi itu bermula dari ide yang digali oleh pengarangnya. Berdasarkan uraian tersebut, maka dapat disimpulkan bahwa menulis cerpen adalah suatu kegiatan melahirkan pikiran dan perasaan, menemukan masalah, menemukan konflik, memberikan informasi, dan menghidupkan kejadian kembali secara utuh, yang memberikan kesan tunggal yang dominan.

Pembelajaran menulis cerpen di SMA membutuhkan model pembelajaran, terutama untuk meningkatkan daya imajinasi siswa. Selain itu, model pembelajaran dalam menulis cerpen dapat meningkatkan kosa kata siswa dalam penyusunan alur, seting, dan karakter tokoh dalam cerpen. Salah satu model pembelajaran yang dinilai sesuai untuk meningkatkan hasil belajar memproduksi cerpen adalah penerapan teknik pembelajaran "CANTIK" Dalam inovasi ini, menurut Nursetyasih (2019) yang dimaksud dengan model pembelajaran "CANTIK" adalah model pembelajaran dengan cara peserta didik mencari ide dan berfantasi. Kemudian, mengabadikan ide dalam bentuk grafik alur bergambar sebagai media, yang akan membantu siswa dalam membuat kerangka kalimat, serta menerapkan struktur dan unsurnya. Kemudian, siswa dapat terus mengembangkan dan memproduksi cerpen. Dengan gambar tersebut, diharapkan dapat merangsang ide atau gagasan serta imajinasi siswa, sehingga siswa dapat menuangkannya ke dalam cerpen dengan lebih mudah.

\section{Metode Penelitian}

Model pembelajaran "CANTIK" adalah Cari inspirasi, Abadikan dalam bentuk grafik alur bergambar, Narasikan menjadi beberapa kalimat, Terapkan strukturnya, Ikat unsurnya, dan Kembangkan. Dalam model pembelajaran ini peserta didik mencari ide dan berfantasi. Kemudian, mengabadikan ide dalam bentuk grafik alur bergambar sebagai media, yang akan membantu siswa dalam membuat kerangka kalimat, serta menerapkan struktur dan unsurnya. Kemudian, siswa dapat terus mengembangkan dan memproduksi cerpen.

\section{Hasil Penelitian dan Pembahasan}

Setelah menerapkan pembelajaran menulis cerpen dengan model pembelajaran "CANTIK" banyak perubahan yang terjadi pada peserta didik. Perubahan itu penulis ketahui dari observasi pada aktifitas peserta didik pada saat mengikuti pembelajaran dan dari hasil cerpen yang diproduksi. Perubahan itu antara lain sebagai berikut: (1) Penerapan Teknik Menulis Cerpen dengan Model Pembelajaran "CANTIK" di SMA Negeri 1 Tawangsari Sangat Sederhana dan Praktis. Proses pembelajaran di kelas peserta didik memperoleh materi menulis cerpen sesuai dengan perencanaan pembelajaran dalam RPP. 
Pembelajaran berdasarkan pada kompetensi isi, kompetensi dasar, indikator pencapaian pembelajaran. Pembelajaran dengan pendekatan saintifik dengan langkah-langkah: (a) mengamati (observasi). (b) menanya. (c) mengumpulkan informasi. (d) Mengasosiasikan. (e) mengkomunikasikan. Penugasan menulis cerpen dengan model pembelajaran "CANTIK" dengan langkah-langkah (a) Cari ide. (b) Abadikan dengan gambar sketsa sederhana. (c) Narasikan menjadi kalimat. (d) Terapkan strukturnya. (e) Ikat unsurunsurnya. (f) Kembangkan. (2) Pembelajaran Berakhir dengan Menghasilkan Cerpen. Produk hasil pembelajaran sudah selesai dibuat dilanjutkan dengan mengkomunikasikan kepada pembaca dalam hal ini adalah peserta didik. Peserta didik mempresentasikan cerpen yang sudah dihasilkan yaitu dengan membacakan secara ekspresif. (3) Pembelajaran menulis cerpen dengan model pembelajaran "CANTIK" berhasil meningkatkan hasil belajar peserta didik. Untuk memperoleh hasil belajar yang maksimal dan akurat, penulis memberikan tugas menulis cerpen sebanyak 2 kali. Tugas pertama belum menggunakan model pembelajaran "CANTIK", yang kedua penulis menerapkan model pembelajaran "CANTIK" dalam menulis cerpen. Hasil yang dicapai setelah melakukan pembelajaran menulis cerpen dengan model pembelajaran "CANTIK" dapat dilihat dengan cara membandingkan nilai hasil menulis cerpen sebelum menggunakan model pembelajaran "CANTIK" dengan hasil menulis cerpen setelah guru menerapkan model pembelajaran "CANTIK". Rata-rata nilai peserta didik naik dari rata-rata 73 sebelum menggunakan model pembelajaran "CANTIK" menjadi rata-rata 80 setelah menggunakan model pembelajaran" CANTIK". Nilai tertinggi juga mengalami peningkatan dari 85 menjadi 90 . Tampak mengalami peningkatan dari 21 peserta didik yang nilainya belum tuntas menjadi 5 peserta didik yang belum tuntas. Kondisi awal sebelum diterapkannya model pembelajaran "CANTIK" prosentase ketuntasan $43 \%$ setelah penerapan model pembelajaran "CANTIK" meningkat menjadi 84\%. Disamping itu peserta didik juga semakin antusias dalam memproduksi cerpen dilanjutkan dengan mengkomunikasikan melalui presentasi di kelas.

Dalam penelitian yang sejenis, Budi (2015) membuktikan bahwa dengan menggunakan media "teks lagu" lebih efektif dibandingkan dengan pembelajaran menullis cerpen tanpa menggunakan media "teks lagu". Namun dalam penelitian tersebut siswa hanya dituntut untuk menuangkan ide berdasarkan isi lirik lagu. Sedangkan penelitian dengan model pembelajaran "CANTIK" ini peneliti berusaha agar siswa dapat menulis cerpen dengan leluasa memilih ide (tema) baik berdasarkan pengalaman orang lain maupun pengalaman sendiri. Siswa juga dibimbing dengan langkah-langkah berikutnya yaitu membuat sketsa, menarasikan, menerapkan struktur cerpen, memadukan unsur-unsur cerpen serta mengembangkan menjadi sebuah cerpen yang menarik. Penelitian lain yang relevan tentang menulis cerpen juga dilakukan oleh Martini, Sarwiji, dan Sumarwati (2016) yang menggunakan metode pembelajaran berbasis pengalaman dan media audio visual untuk menjadikan siswa lebih aktif dalam mengikuti proses pembelajaran menulis cerpen.

\section{Simpulan dan Saran}


(1) Implementasi model pembelajaran 'CANTIK' bagi siswa di SMA Negeri 1 Tawangsari. Model Pembelajaran "CANTIK" ini merupakan model pembelajaran yang menarik dan sederhana untuk diterapkan dalam menulis cerpen. Peserta didik akan aktif untuk mencari dan menemukan ide yang berasal dari pengalaman atau apa yang terjadi disekitar. Peserta didik akan menuangkan alur peristiwa dari ide yang dipilih menjadi sebuah sketsa sederhana kemudian dinarasikan sesuai dengan gaya bahasa peserta didik masing-masing, dengan tidak lupa menerapkan struktur cerpen. Peserta didik mengatur dan merangkai alur demi alur agar menjadi cerita yang padu. Terakhir peserta didik akan mengembangkan cerita yang sudah terbentuk dengan menambahkan dialog-dialog dan gambaran-gambaran yang membuat cerpen lebih hidup

(2) Pembelajaran menulis cerpen dengan model pembelajaran "CANTIK" dibutuhkan kemampuan berpikir, berimajinasi dan kreatif peserta didik. Pada pembelajaran ini yang dinilai adalah proses menemuka sendiri hal baru dan proses kreatif yang berkesinambungan secara tepat dan serasi antara hal baru dengan struktur kognitif yang telah dimiliki siswa. Pada akhirnya akan memperoleh hasil berupa cerpen yang layak untuk dinikmati pembaca.

Berdasarkan simpulan tersebut, maka dapat dikemukakan saran-saran yang dapat diupayakan dalam meningkatkan pembelajaran menulis cerpen siswa, yaitu Pertama bagi guru: (1) untuk meningkatkan pembelajaran menulis cerpen, guru dapat menggunakan model pembelajaran "CANTIK". (2) Guru seyogyanya bisa memilih model pembelajaran yang tepat karena sebenarnya para siswa memiliki kemampuan yang perlu diasah dengan model pembelajaran yang tepat. Kedua bagi Siswa: siswa hendaknya rajin berlatih menulis untuk menuangkan ide secara runtut dan padu guna menghasilkan cerpen yang baik dan menarik. Ketiga, bagi sekolah: (1) penyediaan sarana dan prasarana yang menunjang terciptanya proses pembelajaran yang menyenangkan dan nyaman; (2) kepala sekolah hendaknya memotivasi guru agar memperluas wawasan mengenai model pembelajaran yang kreatif dan inovatif. Keempat, saran bagi peneliti lain: penelitian ini diharapkan mampu memotivasi berkembangnya penelitian-penelitian lain yang lebih inovatif.

\section{Daftar Rujukan}

Ansari Mimi. (2014). Menulis Cerpen Dengan Model Pembelajaran Learning Community Pada Siswa Kelas X SMA. Jurnal Edukasi Kultura.

Harsono Budi. (2015). Peningkatan Keterampilan Menulis Cerpen Melalui Teknik Latihan Terbimbing Dengan Media Teks Lagu Siswa Kelas 9 Smp Negeri 1 Boyolangu Tulungagung. Jurnal PINUS, Volume 1(3).

Listini \& Saraswati. (2017). Meningkatkan Kemampuan Menulis Cerpen Melalui Model Pembelajaran Sinektik Siswa Kelas VII SMP Sandika Sukajadi. Jurnal Bindo Sastra 1, Volume 1(1).

Mastini, Suwandi Sarwiji, \& Sumarwati. (2016). Peningkatan Keterampilan Menulis Cerpen Melalui Metode Pembelajaran Berbasis Pengalaman dan Media Audiovisual pada Sekolah Menengah Pertama. Jurnal S2 Pendidikan Bahasa Indonesia, Volume $1(1)$.

Nursetyasih. (2019). Teknis menulis cerpen dengan "CANTIK. Jawa Pos. Radar Kudus. Pranoto \& Naning. (2007). Creative Writing: Jurus Menulis Pendek. Jakarta: PT ROHTO. 
Rachman Nurpiana Rizki. (2017). Peningkatan Kemampuan Menulis Cerpen Melalui Penggunaan Media Audiovisual Tayangan Televisi "Cermin Kehidupan TRANS 7". Jurnal Diksatrasia, Volume 1(1).

Sumarjo, Jakob \& Saini K. M. (1986). Apresiasi Kesusastraan. Jakarta: Gramedia Indonesia.

Umar Seniwati. (2015). Peningkatan Keterampilan Menulis Cerpen dengan Strategi Copy The Master Melalui Media Audiovisual pada Siswa Kelas IXa SMP Negeri 2 Tolitoli. Jurnal Kreatif Tadulako Online, Volume 4(6). 